\title{
Creation of two-level liquid cooling system of PC
}

\author{
Sergey V. Koynov ${ }^{1}$, Egor A. Tarasov ${ }^{1, *}$ \\ ${ }^{1}$ Tomsk State University, 634050 Tomsk, Russia
}

\begin{abstract}
This paper devoted to creation of two-level liquid cooling system of PC. We found the solution to change a traditional air cooling system for the liquid cooling system with ethylene glycol as a coolant. The cooling system managed to reduce the temperature by up to $4-10{ }^{\circ} \mathrm{C}$ while down time and $\sim 11^{\circ} \mathrm{C}$ while load time.
\end{abstract}

\section{Introduction}

Nowadays technologies of PC components creation, such as CUDA (Compute Unified Device Architecture) hardware architecture or APP (Accelerated Parallel Processing) technology let us use computational models of physical processes we could never use before due to the limitation of computing power. Unfortunately, increase in this capability is accompanied by both energy consumption and heating power growth, later influencing the temperature inside the PC system unit case. Below is the table, showing energy consumption values of a numbers of modern graphics cards and CPUs:

Table 1. Energy Consumption and Cooling Systems Requirements of a Number of Modern CPUs and Graphics Cards.

\begin{tabular}{|l|c|c|}
\hline \multicolumn{1}{|c|}{ CPU Model } & $\begin{array}{c}\text { Thermal Design } \\
\text { Power (TDP) }\end{array}$ & Additional Informantion \\
\hline 1. Intel Core i7-6800K & $140 \mathrm{~W}$ & $\begin{array}{c}\text { Maximum Computer Case Temperature - } \\
66.8^{\circ} \mathrm{C}\end{array}$ \\
\hline 2. AMD FX-9590 & $220 \mathrm{~W}$ & $\begin{array}{c}\text { Maximum Computer Case Temperature - } \\
57{ }^{\circ} \mathrm{C}\end{array}$ \\
\hline 3. Xeon E5-2670 v3 & $120 \mathrm{~W}$ & $\begin{array}{c}\text { Maximum Computer Case Temperature - } \\
84.5^{\circ} \mathrm{C}\end{array}$ \\
\hline \multicolumn{3}{|c|}{ Graphic Cards } \\
\hline CPU Model & $\begin{array}{c}\text { Energy Consump- } \\
\text { tion }\end{array}$ & Additional Informantion \\
\hline 1. Nvidia GeForce GTX 1080 & $180 \mathrm{~W}$ & Maximum GPU Temperature $-94{ }^{\circ} \mathrm{C}$ \\
\hline 2. Nvidia GeForce GTX 980 & $165 \mathrm{~W}$ & Maximum GPU Temperature $-98^{\circ} \mathrm{C}$ \\
\hline 3. Nvidia GeForce GTX 1050 & $75 \mathrm{~W}$ & Maximum GPU Temperature $-97{ }^{\circ} \mathrm{C}$ \\
\hline
\end{tabular}

\footnotetext{
${ }^{*}$ Corresponding author: diomedis@,mail.ru
} 
Utilizing PC in the environment with the temperature higher than certain value may cause a premature failure of different components. Temperature exposure is the reason for PC case crack, mechanical damage of a processor chip (due to thermal growth), electrolyte leakage in condensers or delamination of PC board, where the devices are situated. In case when elements are low powered (chips, RAM) or when constraining computational capacity, cooling system can turn the cooler only without forced air cooling, and it will manage timely heat transfer.

For example, when CPU works at the temperature above maximum for a computer case (see Table 1), it can not only damage the surrounding elements on the motherboard, but also starts throttling. Cooling systems and ways traditionally used in PCs [2,3,4], such as active and passive air-cooling (fans, radiators of intricate geometry), thermal compound on radiators' contacts and heat causing elements (CPU, GPU, northbridge and southbridge) stop coping with the cooling task, and for this reason we need the transition to liquid cooling systems.

\section{Experimental}

PC liquid cooling system we created represents the following. To sink the running temperature of Intel ${ }^{\circledR}$ Core $^{\mathrm{TM}}$ i7-4790K CPU on the GA-Z97X-Gaming G1 WIFI-BK motherboard, we initially used the CBO Deepcool CAPTAIN 360 ready-made solution: water unit material - copper; pump - time per fault is 120000 hours, frequency - $3500 \mathrm{rpm}$; radiator - material: aluminium, sizes: $395 \times 120 \times 32 \mathrm{~mm}$; fans - sizes: 3x 120x120x25 mm; rotational rate: $600 \pm 200 \sim 2200 \pm 10 \% \mathrm{rpm}$.

The run of the solution revealed one more problem with the cooling system of the PC the cooling effect of CPU near the socket had vanished and we needed to set up one more liquid cooling system for the Intel Z97, PLX PEX8747 chips and for the brain of processor power microchip, RAM and GPU. It was necessary for Z97 chip to remain cool, to carry the heat away from the computer case.

After solving a number of engineering tasks we created the given system, which together with ready-made CPU solution comprises a two-level liquid cooling system of PC. In the figure 1 the following elements are presented:

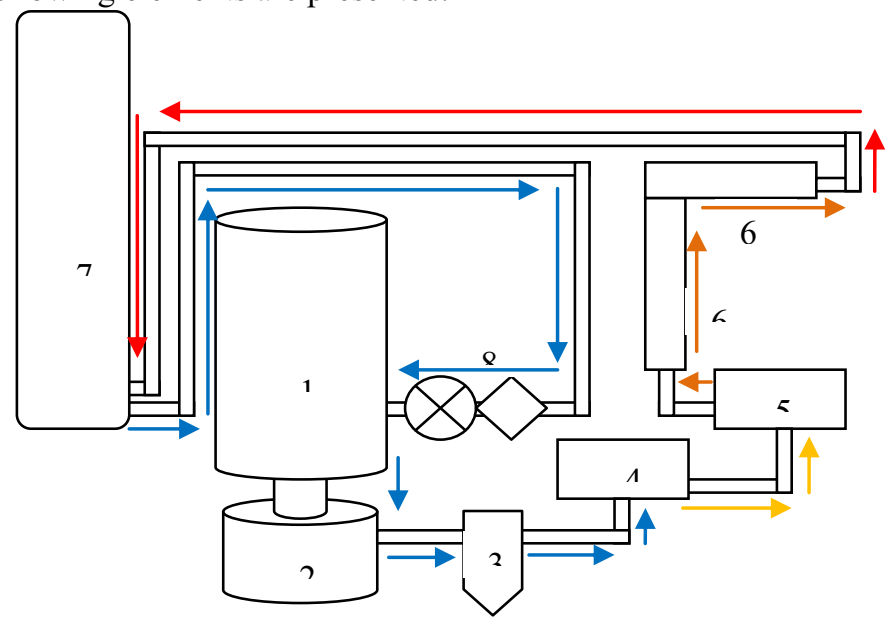

Fig. 1. The second level of liquid cooling system of PC.

1 - liquid container; 2 - MAGICOOL pump; 3 - dump; 4 - water unit (copper) MAN-kd 2013CPU on a Intel Z97 chip; 5 - water unit (copper) KD North Bridge 2015 on a PLX PEX8747 chip; 6a, 6b - big and small radiators VRM (standard radiators for GA-Z97X- 
Gaming G1 WIFI-BK motherboard); 7 - STW R240P radiator (aluminium); 8 - STW flowmeter and a digital thermometer with a display. The arrows show the coolant run.

Having tested the system on a various types of cooling liquids, such as light water (tapwater), service water and service water with ethanol (6 parts water to 4 parts ethanol), we chose Thermaltake C1000 Opaque Coolant. It is ethylene glycol (1,2-dioxiethan) with antioxidants. Main physical and chemical characteristics are represented in the table 2.

Table 2. C1000 Opaque Coolant characteristics.

\begin{tabular}{|l|c|}
\hline \multicolumn{1}{|c|}{ Characteristics } & Value \\
\hline $\mathrm{pH}$ level, $\left(\right.$ at $\left.20^{\circ} \mathrm{C}\right)$ & $8.0-8.5$ \\
\hline Density, $\left(\right.$ at $\left.20^{\circ} \mathrm{C}\right)$ & $1.120-1.125 \mathrm{~g} / \mathrm{cm}^{3}$ \\
\hline Viscosity, (kinematic, at $\left.20{ }^{\circ} \mathrm{C}\right)$ & $20-30 \mathrm{~mm}^{2} / \mathrm{s}$ \\
\hline Boiling point & $\geq 165^{\circ} \mathrm{C}$ \\
\hline Fusing temperature / solidifying point & $\leq-18^{\circ} \mathrm{C}$ \\
\hline
\end{tabular}

To test the resulting system we compared results of VRM stress testing enumerated in [5] with the results of system load and down time:

Table 3. Comparison of experiments' results.

\begin{tabular}{|c|c|c|c|c|}
\hline Data from [5] & $\begin{array}{l}\text { Environmental tem- } \\
\text { perature }\end{array}$ & $\begin{array}{c}\text { CPU } \\
(\text { LGA1150) }\end{array}$ & $\begin{array}{c}\mathrm{PCH} \\
(\text { Intel Z97) }\end{array}$ & $\begin{array}{l}\text { System board } \\
\text { (VRM) }\end{array}$ \\
\hline Down time & \multirow{2}{*}{$\sim 27^{\circ} \mathrm{C}$} & $40.1^{\circ} \mathrm{C}$ & $51.1^{\circ} \mathrm{C}$ & $35.5^{\circ} \mathrm{C}$ \\
\hline Load & & $58.2^{\circ} \mathrm{C}$ & $51.6^{\circ} \mathrm{C}$ & $49.3^{\circ} \mathrm{C}$ \\
\hline \multicolumn{5}{|c|}{$\begin{array}{l}\text { Experimental data received by the authors with the help of temperature sensors, attached to ITE } \\
\text { IT } 8620 \mathrm{E} \text { chip on the motherboard }\end{array}$} \\
\hline Down time & \multirow{2}{*}{$\sim 23{ }^{\circ} \mathrm{C}$} & $32{ }^{\circ} \mathrm{C}$ & $33^{\circ} \mathrm{C}$ & $31^{\circ} \mathrm{C}$ \\
\hline Load & & $43{ }^{\circ} \mathrm{C}$ & $37^{\circ} \mathrm{C}$ & $34^{\circ} \mathrm{C}$ \\
\hline
\end{tabular}

\section{Summary}

As we can see from the temperature sensors, the cooling system managed to sink the temperature by up to $4-10{ }^{\circ} \mathrm{C}$ while down time and $\sim 11{ }^{\circ} \mathrm{C}$ while load time (considering difference in our environmental temperature with the one in the other experiments). The obtained results let us to draw a conclusion about successful application of the created liquid cooling $\mathrm{PC}$ system in the given configuration.

In the future we plan to set up computational models for the description of forced convection processes in this system, using data from previous experiments [6,7] and to cast the modelling results in our further works, and what is more, to compare them with the experimental results.

\section{References}

1. Intel® I/O Controller Hub 10 (ICH10) Family Thermal and Mechanical Design Guidelines. (2008). Document Number: 319975-001319975-001

2. S. Matei, Xtrem PC, 78, 46 (2006)

3. K. Azar, B. Tavassoli, Electroics Cooling, 9 (2), 30 (2003)

4. J.R. Wilson, Military \& Aerospace Electronics, 34 (2006)

5. https://3dnews.ru/903287

6. G.V. Kuznetsov, M.A. Sheremet, Thermophys. Aeromech. 16, 119 (2009)

7. G.V. Kuznetsov, M.A. Sheremet, Russian Microelectronics, 37 (2), 131 (2008) 